\title{
Correlation Analysis of Serum Magnesium Concentration and Lipids in Health Population and Type 2 Diabetes Patients
}

\author{
Han Tuo ${ }^{1,}$, Gong Hong ${ }^{2}{ }^{\dagger}$, Mehreen Fatima ${ }^{3}$, Li Ying ${ }^{1}$, Fan Yajie ${ }^{1}$, Song Wei ${ }^{1}$, Yao Zhihui ${ }^{1}$, \\ Wang Qian $^{2}$, Wang Congxia ${ }^{1, *}$ \\ ${ }^{1}$ Department of Cardiology, the Second Affiliated Hospital of Xi'an Jiaotong University, Xi'an, China \\ ${ }^{2}$ Department of Health Management, the Second Affiliated Hospital of Xi'an Jiaotong University, Xi'an, China \\ ${ }^{3}$ Laboratory Animal Centre, Xi'an Jiaotong University Health Science Centre, Xi'an, China
}

Email address:

hantuo0228@163.com (Han Tuo),1215521709@qq.com (Gong Hong), mehreenfatima410@gmail.com (M. Fatima), liying2021a@163.com (Li Ying),773728632@qq.com (Fan Yajie),3044361672@qq.com (Song Wei), 310262382@qq.com (Yao Zhihui), 948903566@qq.com (Wang Qian),wcx622@163.com (Wang Congxia)

${ }^{*}$ Corresponding author

$\dagger$ Han Tuo and Gong Hong are co-first authors.

\section{To cite this article:}

Han Tuo, Gong Hong, Mehreen Fatima, Li Ying, Fan Yajie, Song Wei, Yao Zhihui, Wang Qian, Wang Congxia. Correlation Analysis of Serum Magnesium Concentration and Lipids in Health Population and Type 2 Diabetes Patients. American Journal of Life Sciences.

Vol. 9, No. 5, 2021, pp. 134-140. doi: 10.11648/j.ajls.20210905.15

Received: October 4, 2021; Accepted: October 30, 2021; Published: November 5, 2021

\begin{abstract}
Background: Cardiovascular disease (CVD) is the lead cause of death around the world. Dyslipidemia is strongly associated with CVD. Magnesium (Mg) is an essential trace element involved in many vital biological process, such as glucose and lipid metabolism. Previous studies have showed that hypomagnesemia or Mg deficiency is associated with an increased risk of type 2 diabetes, metabolic syndrome, hypertension, and CVD. Objective: To explore the correlation between serum magnesium $(\mathrm{Mg})$ concentration and dyslipidemia in health subjects and type 2 diabetes patients. Methods: 3430 health subjects were selected and divided into adult (aged 18 59) and elderly ( $\geq 60$ years) groups according to age. In addition, 63 patients with type 2 diabetes were selected. Propensity score based on age, gender, body mass index (BMI) and smoking history was matched at a ratio of 1:2 between patients and health controls. Results: There was a significant correlation between elevated serum $\mathrm{Mg}$ concentration and dyslipidemia in health adults, but no significant correlation between the two in the health elderly. Multiple linear regression showed that serum total cholesterol (TC), BMI and smoking in men while fasting plasma glucose and serum LDL-C in women were independent risk factors for elevated serum Mg concentration. Whereas, no significant correlation was found between serum Mg concentration and lipid levels in T2DM patients. Conclusion: Serum Mg concentration is correlated with serum lipids to a certain extent, while age, gender and disease status may also exert certain confound effects. The causal relationship between serum $\mathrm{Mg}$ and dyslipidemia needs to be further studied.
\end{abstract}

Keywords: Dyslipidemia, Serum Magnesium, Health Population, Type 2 Diabetes, Propensity Score Matching

\section{Introduction}

Cardiovascular diseases (CVD) is the lead cause that endangers human life and health. Dyslipidemia, hypertension, and hyperglycemia are the crucial risk factors of CVD $[1,2]$. Magnesium $(\mathrm{Mg})$ is a vital trace element inside the human body and participates in more than 300 enzymatic reactions in glucose and lipid metabolism [3]. Studies have reported that hypomagnesemia or $\mathrm{Mg}$ deficiency is associated with an increased risk of type 2 diabetes (T2DM), metabolic syndrome, hypertension, and CVD [4]. Serum Mg concentration significantly decreases in patients with 
dyslipidemia and diabetes $[5,6]$. However, some studies provided different results, especially in patients with chronic kidney disease, long-term hemodialysis or polycystic ovary syndrome [7-9]. The situation seems to be different, even opposite among different disease status. Dyslipidemia is a complex group of lipid metabolism disorders closely related to age, gender, genetics, diets, and environmental factors [2]. However, few studies currently deal with the relationship between serum $\mathrm{Mg}$ concentration and dyslipidemia in the Chinese population, especially among health population.

Based on the health examination data in a tier-3 hospital, we herein explored the link between serum Mg concentration and plasma lipid profiles in health subjects and patients with T2DM, separately. Finally, 3430 health subjects and 63 T2DM patients were included in the final analysis. Propensity score matching was performed to match the confound factors, like age, gender, body mass index (BMI) and smoking between T2DM patients and health control. Correlation and linear regression analysis were applied to explore the link between serum Mg and lipids levels.

\section{Objects and Methods}

\subsection{Study Objects}

The health examination data in our hospital from Sep 2018 to May 2021 were retrospectively retrieved. We included those patients with serum trace elements and plasma lipid testing results. And those with various underlying diseases, incomplete clinical data, or under 18 years old were excluded.

A

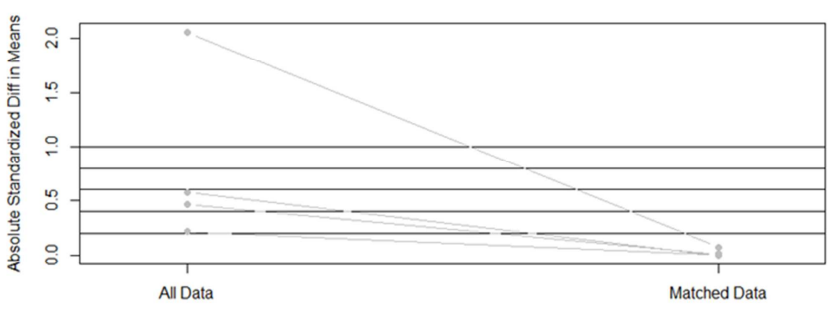

C

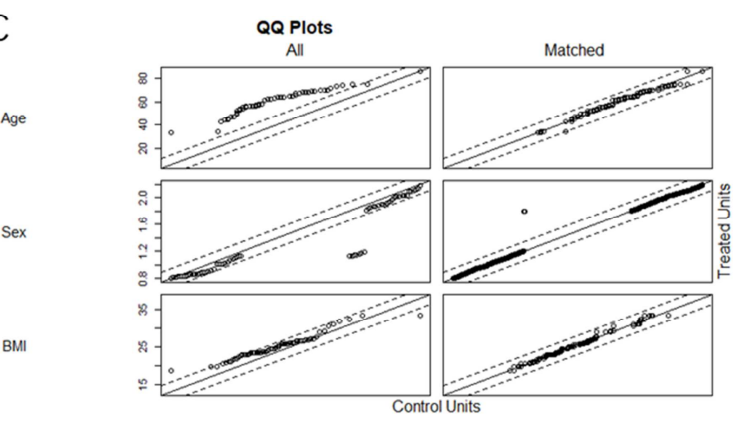

Finally, 3430 subjects were selected, consisting of 1762 (51.4 \%) males and 1668 (48.6\%) females. The average age was $37.9 \pm 12.3$ years old in a left-skewed distribution (minimum 18 and maximum 86 years old). The average serum $\mathrm{Mg}$ concentration was $1.65 \pm 0.25 \mathrm{mmol} / \mathrm{L}$ (Reference range: $1.12-2.16 \mathrm{mmol} / \mathrm{L}$ ) in a normal distribution, (minimum 0.55 $\mathrm{mmol} / \mathrm{L}$ and maximum $3.33 \mathrm{mmol} / \mathrm{L}$ ). In addition, $63 \mathrm{~T} 2 \mathrm{DM}$ patients without other underlying comorbidities were also included, and their anthropometric, serum biochemical and trace element testing results were also collected for analysis. The study was reviewed and approved by the Institutional Clinical Ethics Committee of the Second Affiliated Hospital of Xi'an Jiaotong University and performed according to the Declaration of Helsinki (1964).

\subsection{Anthropometric and Biochemical Measurement}

Standing height, body weight, waist circumference, and hip circumference were measured when the participants were standing with light clothing and without shoes. Body mass index (BMI) was calculated as: $\mathrm{BMI}=$ height $(\mathrm{m}) /$ body weight $2(\mathrm{Kg})$. Baseline blood pressure and heart rate were measured at rest using a validated electronic sphygmomanometer (HEM-7124 from Omron Corp.) Venous blood samples were obtained between 06:00 $\mathrm{h}$ and 09:00 $\mathrm{h}$ after fasting for at least 8 hours. Blood samples were immediately processed and assessed by Beckman automatic biochemical analyzer. The levels of trace elements were determined by BH5100S atomic absorption spectrometer (Beijing Bohui Innovation Technology Co.).

B

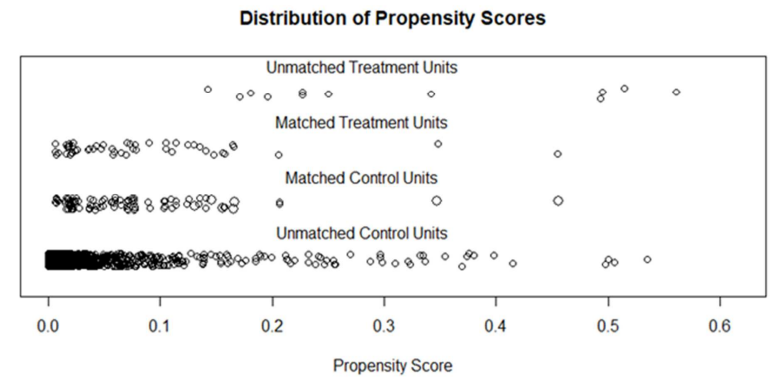

D
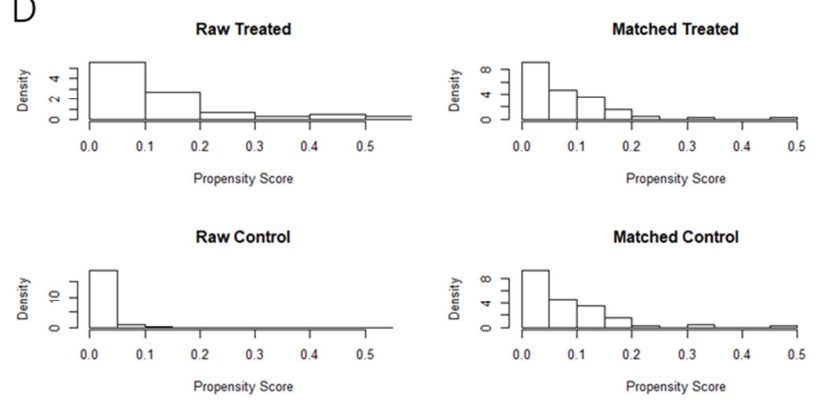

Figure 1. Propensity scores matching results between T2DM patients and health controls. A) Absolute standardized differences in means after matched. B) The distribution of Propensity Scores before and after matched in patients and control groups. C) The QQ plots of Age, Sex and BMI factors after matched. D) The density of Propensity Scores after matched in patients and control groups.

\subsection{Data Analysis}

All data analysis was performed using SPSS version
26.0. A 1:2 propensity score matching was performed using the $\mathrm{R}$ software "MatchIt" package, and baseline characteristics such as age, gender, body mass index (BMI) 
and smoking were included. The matching results are shown in Figure 1. The measurement data were expressed as the mean \pm standard deviation (mean $\pm \mathrm{SD}$ ), whereas the count data were represented as a percentage n (\%). For normally distributed data, the two-sided independent sample t-test was used to compare data between groups. Otherwise, the Mann-Whitney $U$ test was used. Pearson correlation analysis was used for the normally distributed data, and Spearman correlation analysis was used for the data not normally distributed. Multiple linear regression was performed to analyze factors related to serum $\mathrm{Mg}$ concentration. $P$ value less than 0.05 was considered significant.

\section{Results}

\subsection{Baseline Characteristics of Different Age Groups}

A total of 3430 participants were included, consisting of 3208 (93.5\%) adults aged 18 59 and 222 (6.5\%) elderly people aged 60 or above. Comparison between different genders showed that the age, BMI, systolic blood pressure
(SBP), diastolic blood pressure (DBP), smoking history and fasting plasma glucose of adult male were significantly higher than those of adult females (all $P<0.05$ ). In terms of plasma lipids, total cholesterol (TC), triglycerides (TG) and low density lipoprotein cholesterol (LDL-C) in males were significantly higher than females, while high-density lipoprotein (HDL-C) was substantially lower (all $P<0.05$ ). Serum zinc, iron and $\mathrm{Mg}$ concentrations of males were significantly higher than females, while calcium was much lower (all $P<0.05$ ). Those differences explained, at least partly, the susceptibility of men to cardiovascular diseases. Gender differences in SBP disappeared in the elderly, and DBP was slightly higher in men than women. The levels of TC, HDL-C and LDL-C in elderly women were significantly higher than those in elderly men (all $P<0.05$ ), which may be related to the decrease of estrogen level, partly explaining the increased incidence of cardiovascular disease in postmenopausal women. In addition, the gender difference of serum $\mathrm{Mg}$ concentration in the elderly also disappeared $(P=0.543)$, mainly due to the increase of serum $\mathrm{Mg}$ in elderly women (Table 1).

Table 1. Basic characteristics between genders in different age groups.

\begin{tabular}{|c|c|c|c|c|}
\hline & Adult Male & Adult Fem & Old Male & Old Female \\
\hline & $n=1638$ & $n=1570$ & $n=124$ & $n=98$ \\
\hline Age (year) & $37.7 \pm 10.1$ & $34.1 \pm 9.8$ & $65.7 \pm 6.2$ & $65.9 \pm 5.8$ \\
\hline Weight (kg) & $76.1 \pm 10.7$ & $57.0 \pm 5.6$ & $70.9 \pm 10.7$ & $59.3 \pm 8.7$ \\
\hline BMI $\left(\mathrm{kg} / \mathrm{m}^{2}\right)$ & $25.19 \pm 3.24$ & $21.80 \pm 3.06$ & $24.59 \pm 3.13$ & $24.20 \pm 2.23$ \\
\hline $\mathrm{WC}(\mathrm{cm})$ & $85.8 \pm 8.9$ & $71.4 \pm 8.2$ & $86.7 \pm 9.0$ & $81.1 \pm 8.7$ \\
\hline $\mathrm{HC}(\mathrm{cm})$ & $96.3 \pm 6.1$ & $90.2 \pm 6.2$ & $95.6 \pm 6.0$ & $93.8 \pm 6.2$ \\
\hline HR (bpm) & $75.7 \pm 8.3$ & $78.6 \pm 10.0$ & $72.7 \pm 7.5$ & $72.9 \pm 9.9$ \\
\hline SBP (mmHg) & $122.4 \pm 13.7$ & $114.5 \pm 12.6$ & $133.8 \pm 16.4$ & $136.6 \pm 18.9$ \\
\hline DBP (mmHg) & $80.6 \pm 10.7$ & $73.6 \pm 9.5$ & $84.1 \pm 10.1$ & $81.0 \pm 11.8$ \\
\hline Smoke (n (\%)) & $231(16.9 \%)$ & $2(0.1 \%)$ & $14(11.2 \%)$ & $0(0.0 \%)$ \\
\hline $\operatorname{ALT}(\mathrm{U} / \mathrm{L})$ & $28.96 \pm 20.29$ & $16.22 \pm 14.33$ & $21.06 \pm 9.18$ & $17.27 \pm 8.74$ \\
\hline AST (U/L) & $22.89 \pm 9.86$ & $19.00 \pm 10.00$ & $22.26 \pm 7.48$ & $21.55 \pm 6.39$ \\
\hline $\mathrm{TP}(\mathrm{g} / \mathrm{L})$ & $71.29 \pm 4.78$ & $72.36 \pm 4.68$ & $69.76 \pm 4.67$ & $72.02 \pm 5.16$ \\
\hline $\operatorname{ALB}(\mathrm{g} / \mathrm{L})$ & $46.15 \pm 2.96$ & $45.49 \pm 2.80$ & $43.68 \pm 2.73$ & $43.83 \pm 3.10$ \\
\hline FPG $(\mathrm{mmol} / \mathrm{L})$ & $5.28 \pm 1.30$ & $4.89 \pm 0.50$ & $5.75 \pm 4.58$ & $5.39 \pm 0.87$ \\
\hline $\mathrm{TC}(\mathrm{mmol} / \mathrm{L})$ & $4.44 \pm 0.88$ & $2.30 \pm 0.85$ & $4.36 \pm 0.85$ & $4.96 \pm 0.96$ \\
\hline $\mathrm{TG}(\mathrm{mmol} / \mathrm{L})$ & $1.86 \pm 1.43$ & $1.06 \pm 0.69$ & $1.47 \pm 0.66$ & $1.51 \pm 0.53$ \\
\hline $\mathrm{HDL}-\mathrm{C}(\mathrm{mmol} / \mathrm{L})$ & $1.14 \pm 0.24$ & $1.47 \pm 0.33$ & $1.24 \pm 0.29$ & $1.40 \pm 0.31$ \\
\hline LDL-C $(\mathrm{mmol} / \mathrm{L})$ & $2.84 \pm 0.72$ & $2.57 \pm 0.76$ & $2.74 \pm 0.76$ & $3.18 \pm 0.90$ \\
\hline BUN (mmol/L) & $4.85 \pm 1.15$ & $4.08 \pm 1.09$ & $5.17 \pm 1.39$ & $4.68 \pm 1.08$ \\
\hline $\mathrm{Cre}(\mu \mathrm{mol} / \mathrm{L})$ & $74.10 \pm 10.84$ & $54.76 \pm 9.46$ & $72.98 \pm 14.50$ & $56.69 \pm 11.50$ \\
\hline $\mathrm{Zn}(\mu \mathrm{mol} / \mathrm{L})$ & $102.6 \pm 18.94$ & $92.24 \pm 16.83$ & $104.2 \pm 18.55$ & $94.00 \pm 16.82$ \\
\hline $\mathrm{Fe}(\mathrm{mmol} / \mathrm{L})$ & $9.43 \pm 1.15$ & $9.18 \pm 0.92$ & $9.11 \pm 1.03$ & $8.28 \pm 0.90$ \\
\hline $\mathrm{Ca}(\mathrm{mmol} / \mathrm{L})$ & $1.57 \pm 0.14$ & $1.63 \pm 0.14$ & $1.50 \pm 0.16$ & $1.61 \pm 0.17$ \\
\hline $\mathrm{Mg}(\mathrm{mmol} / \mathrm{L})$ & $1.72 \pm 0.26$ & $1.56 \pm 0.23$ & $1.69 \pm 0.27$ & $1.67 \pm 0.22$ \\
\hline
\end{tabular}

Abbreviations: WC, Waist circumference; HC, Hip circumference; ALT, Alanine aminotransferase; AST, Aspartate transaminase; TP, Total protein; ALB, Albumin; FBG, Fasting plasma glucose; BUN, Urea nitrogen; Cre, Creatinine; Zn, Zinc; Fe, Iron; Ca, Calcium; Mg, Magnesium.

\subsection{Correlation Between Serum Mg and Plasma Lipids}

Correlation analysis revealed that the serum $\mathrm{Mg}$ level in health adults was significantly correlated with plasma TC, TG, and LDL-C, but not HDL-C $(P=0.774)$. The correlation coefficients were $0.141,0.132$ and 0.121 , respectively. In addition, the results of sex subgroups were consistent. However, there was no significant correlation between serum $\mathrm{Mg}$ and plasma lipid and glucose levels in the elderly without underlying diseases (Table 2). 
Table 2. Correlation of plasma glucose, lipids and serum $\mathrm{Mg}$ in health population.

\begin{tabular}{lllllllll}
\hline & \multicolumn{2}{l}{ Adult Male $(\mathbf{n}=\mathbf{1 6 3 8})$} & \multicolumn{2}{c}{ Adult Female $(\mathbf{n}=\mathbf{1 5 7 0})$} & \multicolumn{2}{c}{ Old Male $(\mathbf{n}=124)$} & \multicolumn{2}{c}{ Old Female $(\mathbf{n}=\mathbf{9 8})$} \\
\cline { 2 - 9 } & $\boldsymbol{r}$ & $\boldsymbol{P}$ & $\boldsymbol{r}$ & $\boldsymbol{P}$ & $\boldsymbol{r}$ & $\boldsymbol{P}$ & $\boldsymbol{r}$ \\
\hline FBG & 0.020 & 0.430 & 0.146 & $<0.001$ & 0.009 & 0.921 & 0.050 & 0.629 \\
TC & 0.141 & $<0.001$ & 0.121 & $<0.001$ & 0.089 & 0.324 & 0.090 \\
TG & 0.132 & $<0.001$ & 0.123 & $<0.001$ & 0.101 & 0.265 & 0.154 & 0.380 \\
HDL-C & -0.008 & 0.774 & 0.010 & 0.746 & -0.011 & 0.900 & 0.098 & 0.336 \\
LDL-C & 0.121 & $<0.001$ & 0.115 & $<0.001$ & 0.013 & 0.885 & 0.049 & 0.630 \\
\hline
\end{tabular}

\subsection{Linear Regression Analysis on Factors of Serum Mg}

Multiple linear regression analysis showed that serum TC $(B=0.027,95 \% C I: 0.010 \sim 0.045)$, BMI $(B=0.005,95 \% C I$ : $0.001 \sim 0.010)$ and smoking $(B=0.045,95 \% C I: 0.004 \sim$
$0.086)$ in health adult males, while fasting plasma glucose $(B=0.071,95 \% C I: 0.039 \sim 0.103)$ and LDL-C $(B=0.031$, 95\% $C I: 0.003 \sim 0.010)$ in females were independent risk factors for elevated serum $\mathrm{Mg}$ concentration (Table 3).

Table 3. Linear regression analysis of factors related to serum $\mathrm{Mg}$ concentration in health adults.

\begin{tabular}{|c|c|c|c|c|}
\hline & B & $95 \% \mathrm{CI}$ & $\mathbf{t}$ & $\mathbf{P}$ \\
\hline \multicolumn{5}{|l|}{ Male } \\
\hline constant & 1.451 & $1.324 \sim 1.579$ & 22.326 & $<0.001$ \\
\hline $\mathrm{TC}(\mathrm{mmol} / \mathrm{L})$ & 0.027 & $0.010 \sim 0.045$ & 3.124 & 0.002 \\
\hline BMI $\left(\mathrm{kg} / \mathrm{m}^{2}\right)$ & 0.005 & $0.001 \sim 0.010$ & 2.226 & 0.026 \\
\hline Smoke & 0.045 & $0.004 \sim 0.086$ & 2.145 & 0.032 \\
\hline \multicolumn{5}{|l|}{ Female } \\
\hline FBG $(\mathrm{mmol} / \mathrm{L})$ & 0.071 & $0.039 \sim 0.103$ & 4.388 & $<0.001$ \\
\hline LDL-C (mmol/L) & 0.031 & $0.003 \sim 0.010$ & 2.935 & 0.003 \\
\hline
\end{tabular}

\subsection{Basic Characteristics of T2DM Patients}

63 T2DM patients were enrolled, including 39 males $(61.9 \%)$ and 24 females $(38.1 \%)$. The average age was $58.9 \pm 10.3$ years, and the average fasting plasma glucose was $8.73 \pm 2.81 \mathrm{mmol} / \mathrm{L}$. Comparison between groups indicated no significant difference in serum $\mathrm{Mg}$ concentration between T2DM patients and health controls $(1.65 \pm 0.25$ vs $1.68 \pm 0.20 \mathrm{mmol} / \mathrm{L}$,
$\mathrm{P}=0.187$ ). Given the significant difference in baseline characteristics between the groups, the propensity score matching was performed according to age, gender, BMI and smoking, and 126 health control groups were matched at the ratio of 1:2. There was still no significant difference in serum $\mathrm{Mg}$ level between the two groups after matching $(1.72 \pm 0.27 \mathrm{vs}$ $1.68 \pm 0.20 \mathrm{mmol} / \mathrm{L}, \mathrm{P}=0.228$, Table 4).

Table 4. Comparison of serum lipids and trace elements between T2DM patients and health controls.

\begin{tabular}{|c|c|c|c|c|}
\hline & \multicolumn{2}{|l|}{ Pre-PSM } & \multicolumn{2}{|l|}{ Post-PSM } \\
\hline & Control $(n=3430)$ & T2DM $(n=63)$ & Control $(n=126)$ & T2DM $(n=63)$ \\
\hline Age (year) & $37.7 \pm 12.5$ & $58.9 \pm 10.3$ & $58.0 \pm 10.2$ & $58.9 \pm 10.3$ \\
\hline Female n (\%) & $1668(48.6)$ & $24(38.1)$ & $48(38.1)$ & $24(38.1)$ \\
\hline Weight (kg) & $66.6 \pm 13.5$ & $69.5 \pm 12.5$ & $68.8 \pm 11.7$ & $69.5 \pm 12.5$ \\
\hline BMI $\left(\mathrm{kg} / \mathrm{m}^{2}\right)$ & $23.56 \pm 3.56$ & $25.04 \pm 3.19$ & $25.00 \pm 3.21$ & $25.04 \pm 3.19$ \\
\hline SBP (mmHg) & $119.5 \pm 14.6$ & $133.5 \pm 12.8$ & $129.6 \pm 17.4$ & $133.5 \pm 12.8$ \\
\hline DBP (mmHg) & $77.5 \pm 10.9$ & $81.8 \pm 10.0$ & $80.7 \pm 10.2$ & $81.8 \pm 10.0$ \\
\hline $\mathrm{TP}(\mathrm{g} / \mathrm{L})$ & $71.71 \pm 4.79$ & $72.12 \pm 5.04$ & $70.68 \pm 4.64$ & $70.92 \pm 10.57$ \\
\hline $\operatorname{ALB}(g / L)$ & $45.70 \pm 2.95$ & $45.35 \pm 3.04$ & $44.04 \pm 2.76$ & $44.60 \pm 6.58$ \\
\hline FBG (mmol/L) & $5.12 \pm 1.04$ & $8.60 \pm 3.00$ & $5.34 \pm 1.38$ & $8.60 \pm 3.00$ \\
\hline $\mathrm{TC}(\mathrm{mmol} / \mathrm{L})$ & $4.39 \pm 0.88$ & $4.31 \pm 0.86$ & $4.64 \pm 0.81$ & $4.31 \pm 0.86$ \\
\hline $\mathrm{TG}(\mathrm{mmol} / \mathrm{L})$ & $1.49 \pm 1.18$ & $2.13 \pm 1.99$ & $1.74 \pm 0.88$ & $2.13 \pm 1.99$ \\
\hline HDL-C (mmol/L) & $1.29 \pm 0.32$ & $1.15 \pm 0.28$ & $1.24 \pm 0.30$ & $1.15 \pm 0.28$ \\
\hline LDL-C (mmol/L) & $2.73 \pm 0.76$ & $2.53 \pm 0.71$ & $2.96 \pm 0.79$ & $2.53 \pm 0.71$ \\
\hline $\operatorname{Cre}(\mu \mathrm{mol} / \mathrm{L})$ & $64.76 \pm 14.15$ & $67.52 \pm 13.44$ & $66.19 \pm 17.77$ & $67.52 \pm 13.44$ \\
\hline $\mathrm{Zn}(\mu \mathrm{mol} / \mathrm{L})$ & $97.68 \pm 18.66$ & $104.7 \pm 19.11$ & $100.1 \pm 17.38$ & $104.7 \pm 19.11$ \\
\hline $\mathrm{Fe}(\mathrm{mmol} / \mathrm{L})$ & $8.81 \pm 1.21$ & $8.89 \pm 1.10$ & $8.90 \pm 1.27$ & $8.89 \pm 1.10$ \\
\hline $\mathrm{Ca}(\mathrm{mmol} / \mathrm{L})$ & $1.59 \pm 0.15$ & $1.56 \pm 0.14$ & $1.54 \pm 0.15$ & $1.56 \pm 0.14$ \\
\hline $\mathrm{Mg}(\mathrm{mmol} / \mathrm{L})$ & $1.65 \pm 0.25$ & $1.68 \pm 0.20$ & $1.72 \pm 0.27$ & $1.68 \pm 0.20$ \\
\hline
\end{tabular}




\subsection{Correlation Analysis of Serum Mg and Plasma Lipids in T2DM Patients}

Correlation analysis confirmed that there was no correlation between serum $\mathrm{Mg}$ and plasma lipids or fasting plasma glucose in patients with T2DM (all $P>0.05$ ), and the results were consistent in different genders (Table 5).

Table 5. Correlation of plasma glucose, lipids and serum $M g$ in T2DM patients.

\begin{tabular}{lllll}
\hline & \multicolumn{2}{c}{ Male $(\mathbf{n}=\mathbf{3 9})$} & \multicolumn{2}{c}{ Female $(\mathbf{n}=\mathbf{2 4})$} \\
\cline { 2 - 5 } & $\mathbf{r}$ & $\mathbf{P}$ & $\mathbf{r}$ & $\mathbf{P}$ \\
\hline FBG $(\mathrm{mmol} / \mathrm{L})$ & -0.123 & 0.455 & 0.354 & 0.097 \\
TC $(\mathrm{mmol} / \mathrm{L})$ & -0.032 & 0.848 & 0.235 & 0.269 \\
TG $(\mathrm{mmol} / \mathrm{L})$ & 0.172 & 0.294 & -0.239 & 0.260 \\
HDL-C $(\mathrm{mmol} / \mathrm{L})$ & -0.273 & 0.093 & 0.384 & 0.064 \\
LDL-C $(\mathrm{mmol} / \mathrm{L})$ & -0.205 & 0.211 & 0.114 & 0.595 \\
\hline
\end{tabular}

\section{Discussion}

$\mathrm{Mg}$ is one of the essential trace elements and participates in more than 300 enzymatic reactions, such as ATP syntheses inside the human body, like glucose and lipid metabolism and lipid peroxidation. $\mathrm{Mg}$ is primarily an intracellular ion, second only to potassium, which is involved in the regulation of muscle contraction, nerve conduction and vascular tension [4]. The average content of $\mathrm{Mg}$ in the human body is about $20 \sim 28 \mathrm{~g}$, of which $50 \sim 65 \%$ is found in bone tissue, $34 \sim 39 \%$ is located in skeletal muscle, soft tissue and other primary organs. In contrast, $\mathrm{Mg}$ ions in serum only account for less than $1 \%$ of the body's $\mathrm{Mg}$ content. $\mathrm{Mg}$ is mainly absorbed in the small intestine, excreted and reabsorbed in the kidney, and can be mobilized into circulation from bone or muscle tissue to maintain the homeostasis of serum $\mathrm{Mg}$ [3]. $\mathrm{Mg}$ deficiency or under-intake is common in European and American populations, which may be associated with lower levels of $\mathrm{Mg}$ in western diets and modern crops $[4,10]$.

Hypomagnesemia is closely related to cardiovascular and metabolic diseases, such as type 2 diabetes, metabolic syndrome, hypertension, arrhythmia, and coagulopathy [4]. The serum $\mathrm{Mg}$ concentration in patients with metabolic syndrome was significantly decreased $[5,11]$, which was an independent risk factor for dyslipidemia $(O R 2.8,95 \%$ CI: 1.3-2.9) [5], and correlated with the occurrence of metabolic obesity in average weight [12]. The serum $\mathrm{Mg}$ level in patients with T2DM was also much lower that health controls $(1.68 \pm 0.4$ vs $2.20 \pm 0.4 \mathrm{mg} / \mathrm{dL})$ [6], and the TG level was significantly elevated in patients with lower serum $\mathrm{Mg}$ than those with higher serum $\mathrm{Mg}$ [13]. Serum $\mathrm{Mg}$ in patients with rheumatoid arthritis was negatively correlated with $\mathrm{TC}$ and LDL-C and positively correlated with HDL-C [14]. In addition, TC, TG and LDL-C in the population with low serum $\mathrm{Mg}(<1.6 \mathrm{mg} / \mathrm{dL})$ or insufficient $\mathrm{Mg}$ intake $(\leq 350$ $\mathrm{mg} / \mathrm{d}$ ) were significantly higher than those with high serum $\mathrm{Mg}$ or intake. At the same time, HDL-C was significantly lower [15]. The CARDIAC study included 4211 participants from 22 countries and found that the prevalence of hypercholesterolemia in quintiles with the lowest serum $\mathrm{Mg} /$ creatinine ratio was 2.06 times higher than that in the highest quintiles $(95 \% \mathrm{CI}$ : 1.63-2.62). The above results show that hypomagnesemia or insufficient $\mathrm{Mg}$ intake is closely related to dyslipidemia.

However, many other studies showed negative or even opposite results, especially in health populations or some special status, such as chronic kidney diseases, long-term dialysis and polycystic ovary patients. There was no correlation between serum $\mathrm{Mg}$ and lipid components among young and health medical students (average age 22.3 years old) [17]. During the 8-year follow-up of 15 children with primary familial hypomagnesemia (mean serum $\mathrm{Mg} 0.53$ $\mathrm{mmol} / \mathrm{L}$ ), no dyslipidemia, arrhythmia and sudden cardiac death were observed [18], which may due to the small number of cases in this study. In patients with long-term hemodialysis, serum $\mathrm{Mg}$ was positively correlated with lipoprotein (a), HDL and TG, but not LDL-C and TC $[8,19]$. For patients with polycystic ovary, no correlation was found between serum $\mathrm{Mg}$ and dyslipidemia [20]. Another study included 1466 adults (aged 22-81 years), and found that serum $\mathrm{Mg}$ in the dyslipidemia group was higher than that in the regular group ( $24 \mathrm{vs} 23 \mathrm{mg} / \mathrm{L}$ ) [21]. This study found that serum $\mathrm{Mg}$ increased, rather than decreased, significantly correlated with dyslipidemia in health adults, consistent with previous studies $[8,19,21]$. Multiple linear regression revealed that TC, BMI and smoking in men while fasting plasma glucose and LDL-C in women were independent risk factors for elevated serum $\mathrm{Mg}$ concentration. There was no significant correlation between serum $\mathrm{Mg}$ and plasma lipid levels in health elderly population or T2DM patients, and the results in gender subgroups were consistent.

Currently, clinical trial results of exogenous $\mathrm{Mg}$ supplementation in improving dyslipidemia are also controversial. Patients with hyperlipidemia were treated with $350 \mathrm{mg}$ Mg-chlorophenoxyisobutyrate and $250 \mathrm{mg}$ midinositol hexanoate compound 3 times a day for two consestive months. The plasma TC level and TG were significantly reduce by $16 \sim 20 \%$ and $36 \sim 49 \%$, respectively [22]. In patients with hyperlipidemia, oral $\mathrm{Mg}$ supplementation $(500 \mathrm{mg} /$ day $)$ based on a low calorie and low cholesterol diet can reduce plasma TG level but not affect TC [23]. In patients with hypercholesterolemia treated with $150 \mathrm{mg}$ of $\mathrm{Mg}$ pyridoxal-5 ' -phosphate glutamate (MPPG) three times a day for 12 months, there was no difference in plasma TC and other lipid components between the two groups [24]. In patients with renal insufficiency, MPPG $50 \mathrm{mg}$ (3 times/day) treatment for 12 weeks can significantly improve plasma TC, TG and LDL-C levels [25]. In addition, patients with hypercholesterolemia and hypertriglyceridemia treated with magnesium oxide $3 \mathrm{~g} /$ day for 6 weeks, plasma TC, TG were not significantly improved [26]. In another randomized controlled trial among T2DM patients, given magnesium oxide $500 \mathrm{mg} /$ day for two months, compared with placebo, HDL-C and TG did not get improved after treatment [27]. 
Dyslipidemia is a disorder of lipid metabolism and an integral part of metabolic syndrome, including hypertriglyceridemia, low high-density lipoproteinemia, hypercholesterolemia, mixed hyperlipidemia and many apolipoprotein abnormalities. It is closely related to age, gender, genetics, diet and many other environmental factors. The serum $\mathrm{Mg}$ only accounts for less than $1 \%$ of the entire $\mathrm{Mg}$ content in the human body; even the Mg content in red blood cells is more than three times that in serum. Among them, $70 \%$ exist in the form of free ions, and the rest are combined with albumin [3]. In addition, the excretion and reabsorption of $\mathrm{Mg}$ ions in the kidney are dependent on the serum $\mathrm{Mg}$ level. $\mathrm{Mg}$ in bone and muscle tissues can be mobilized into the circulation to maintain the dynamic balance of serum $\mathrm{Mg}[3,4]$. Therefore, the existing studies on the correlation between serum $\mathrm{Mg}$ and plasma lipids often yielded controversial results due to the differences in the study population, $\mathrm{Mg}$ detection method and confounding factors control. However, results from animal experiments are usually consistent.

High-fat diet-fed rabbits or rodents can be observed in serum $\mathrm{Mg}$ ions decreased $[28,29]$. This may be due to the activation of the isoprenoid pathway during cholesterol synthesis, resulting in digoxin by-products. It can inhibit the activity of $\mathrm{Na}+-\mathrm{K}+$-ATPase on the cell membrane and cause the lack of $\mathrm{Mg}$ in the intercellular space. In addition, $\mathrm{Mg}$ can also bind to lipoprotein. The increase of serum $\mathrm{Mg}$ binding to protein in patients with hyperlipidemia [31] may also decrease serum-free $\mathrm{Mg}$ ion concentration. Hypomagnesemia can lead to low inflammatory response and oxidative stress in the body, thereby increasing the risk of dyslipidemia [32]. $\mathrm{Mg}$ supplementation can significantly reduce plasma lipid levels and liver and lipid deposition on the vascular wall [33, 34]. However, experimental animals cannot accurately reflect the actual situation of dyslipidemia in clinical practice due to their single genetic background, controllable intervention factors and short modelling period. In addition, renal insufficiency and insulin resistance can also significantly affect plasma lipids and serum $\mathrm{Mg}$ levels, which may cause apparent differences between different studies in patients with long-term dialysis or hyperglycemia.

This study also has some limitations. First of all, this study is a single-center cross-sectional survey. Therefore, the conclusion can only prompt correlation but cannot infer causal link. Second, the participants' lack of dietary nutrition survey failed to correct the impact of $\mathrm{Mg}$ intake on the results. Finally, the lack of drug use in patients with T2DM may interfere with serum $\mathrm{Mg}$ or lipid levels, shield a shadow on the results.

\section{Conclusion}

In summary, this study found a specific positive correlation between serum $\mathrm{Mg}$ concentration and dyslipidemia, and it was potentially affected by age, gender and disease status. The causal correlation between them remains to be further explored.

\section{Funding}

This work was supported by the National Natural Science Foundation of China (No.81273878).

\section{Disclosure Statement}

All the authors had reached agreement for the publication and declared that there is no conflict of interests.

\section{Author Contribution}

Wang Congxia and Wang Qian conceived the research; Han Tuo, Gong Hong and Fan Yajie collected the original data; Song Wei and Yao Zhihui were responsible for the data analysis; Han Tuo and Li Ying wrote the manuscript; Mehreen Fatima revised the article. Wang Congxia is the guarantor of this work and had full access to all the data in the study and takes responsibility for the integrity of the data and the accuracy of the data analysis.

\section{Data Availability Statement}

The data that support the findings of this study are available from the corresponding author, Wang Congxia, upon reasonable request.

\section{References}

[1] Alloubani A, Nimer R, Samara R. Relationship between hyperlipidemia, cardiovascular disease and stroke: a systematic review [J]. Curr Cardiol Rev. 2020.

[2] Karr S. Epidemiology and management of hyperlipidemia [J]. Am J Manag Care. 2017, 23 (9 Suppl): S139-s48.

[3] Fiorentini D, Cappadone C, Farruggia G, et al. Magnesium: biochemistry, nutrition, detection, and social impact of diseases linked to its deficiency [J]. Nutrients. 2021, 13 (4).

[4] Severino P, Netti L, Mariani MV, et al. Prevention of cardiovascular disease: screening for magnesium deficiency [J] Cardiol Res Pract. 2019, 2019: 4874921.

[5] Guerrero-Romero F, Rodríguez-Morán M. Low serum magnesium levels and metabolic syndrome [J]. Acta Diabetol. 2002, 39 (4): 209-13.

[6] Rusu M, Cristea V, Frenţiu T, et al. Magnesium and selenium in diabetics with peripheral artery disease of the lower limbs [J]. Clujul Med. 2013, 86 (3): 235-9.

[7] Mitwalli AH. Why are serum magnesium levels lower in Saudi dialysis patients? [J] J Taibah Univ Med Sci. 2017, 12 (1): 41-6.

[8] Nasri H, Baradaran A. Correlation of serum magnesium with dyslipidemia in maintenance hemodialysis patients [J]. Acta Medica 2004, 47 (4): 263-5.

[9] Kauffman RP, Tullar PE, Nipp RD, et al. Serum magnesium concentrations and metabolic variables in polycystic ovary syndrome [J]. Acta Obstet Gynecol Scand. 2011, 90 (5): 452-8. 
[10] Workinger JL, Doyle RP, Bortz J. Challenges in the diagnosis of magnesium status [J]. Nutrients. 2018, 10 (9).

[11] Ghasemi A, Zahediasl S, Syedmoradi L, et al. Low serum magnesium levels in elderly subjects with metabolic syndrome [J]. Biol Trace Elem Res. 2010, 136 (1): 18-25.

[12] Guerrero-Romero F, Rodriguez-Moran M. Serum magnesium in the metabolically-obese normal-weight and healthy-obese subjects [J]. Eur J Intern Med. 2013, 24 (7): 639-43.

[13] Srinivasan AR, Niranjan G, Kuzhandai Velu V, et al. Status of serum magnesium in type 2 diabetes mellitus with particular reference to serum triacylglycerol levels [J]. Diabetes Metab Syndr. 2012, 6 (4): 187-9.

[14] Chavan VU, Ramavataram D, Patel PA, et al. Evaluation of serum magnesium, lipid profile and various biochemical parameters as risk factors of cardiovascular diseases in patients with rheumatoid arthritis [J]. J Clin Diagn Res. 2015, 9 (4): Bc01-5.

[15] Mahalle N, Kulkarni MV, Naik SS. Is hypomagnesaemia a coronary risk factor among Indians with coronary artery disease? [J] J Cardiovasc Dis Res. 2012, 3 (4): 280-6.

[16] Yamori Y, Sagara M, Mizushima S, et al. An inverse association between magnesium in 24-h urine and cardiovascular risk factors in middle-aged subjects in 50 CARDIAC Study populations [J]. Hypertens Res. 2015, 38 (3): 219-25.

[17] Miturzyńska-Stryjecka H, Horubała-Bielak G, Markiewicz M. Concentration of magnesium and lipids in blood serum in a group of young healthy medical students [J]. Wiad Lek. 1993, 46 (3-4): 81-6.

[18] Shalev H, Phillip M, Galil A, et al. Clinical presentation and outcome in primary familial hypomagnesaemia [J]. Arch Dis Child. 1998, 78 (2): 127-30.

[19] Ansari MR, Maheshwari N, Shaikh MA, et al. Correlation of serum magnesium with dyslipidemia in patients on maintenance hemodialysis [J]. Saudi J Kidney Dis Transpl. 2012, 23 (1): 21-5.

[20] Sharifi F, Mazloomi S, Hajihosseini R, et al. Serum magnesium concentrations in polycystic ovary syndrome and its association with insulin resistance [J]. Gynecol Endocrinol. 2012, 28 (1): 7-11.

[21] Liu A, Xu P, Gong C, et al. High serum concentration of selenium, but not calcium, cobalt, copper, iron, and magnesium, increased the risk of both hyperglycemia and dyslipidemia in adults: A health examination center based cross-sectional study [J]. J Trace Elem Med Biol. 2020, 59: 126470.

[22] Fischer M, Falkensammer C. New drug combination for medical management of hyperlipemia: clinical study [J]. Int $\mathrm{J}$ Clin Pharmacol Biopharm. 1977, 15 (12): 585-9.
[23] Kisters K, Spieker C, Tepel M, et al. New data about the effects of oral physiological magnesium supplementation on several cardiovascular risk factors (lipids and blood pressure) $[\mathrm{J}]$. Magnes Res. 1993, 6 (4): 355-60.

[24] Schuitemaker GE, van der Pol GA, Aretz CP, et al. A placebo-controlled, double-blind, randomized trial of magnesium-pyridoxal-5'-phosphate-glutamate for hypercholesterolemia and other clinical-chemical risk factors of cardiovascular disease in a primary care setting [J]. Eur J Clin Pharmacol. 2001, 56 (12): 857-63.

[25] Kirsten R, Heintz B, Nelson K, et al. Magnesium pyridoxal 5-phosphate glutamate reduces hyperlipidemia in patients with chronic renal insufficiency [J]. Eur J Clin Pharmacol. 1988, 34 (2): 133-7.

[26] Petersen B, Christiansen C, Hansen PF. Treatment of hypercholesterolemia and hypertriglyceridemia with magnesium [J]. Acta Med Scand. 1976, 200 (1-2): 59-61.

[27] Rashvand S, Mobasseri M, Tarighat-Esfanjani A. Effects of choline and magnesium concurrent supplementation on coagulation and lipid profile in patients with type 2 diabetes mellitus: a Pilot Clinical Trial [J]. Biol Trace Elem Res. 2020, 194 (2): 328-35.

[28] Rademeyer LJ, Booyens J. The effects of variations in the fat and carbohydrate content of the diet on the levels of magnesium and cholesterol in the serum of white rats $[\mathrm{J}]$. Br J Nutr. 1965, 19: 153-62.

[29] Dai B, Li X, Xu J, et al. Synergistic effects of magnesium ions and simvastatin on attenuation of high-fat diet-induced bone loss [J]. Bioact Mater. 2021, 6 (8): 2511-22.

[30] Kumar AR, Kurup PA. Membrane Na+ K+ ATPase inhibition related dyslipidemia and insulin resistance in neuropsychiatric disorders [J]. Indian J Physiol Pharmacol. 2001, 45 (3): 296-304.

[31] Müller G, Pfordte K. Ultrafiltrable and protein-bound magnesium in serum of patients with hyperlipidaemia [J]. Clin Chim Acta. 1970, 30 (3): 583-6.

[32] Evangelopoulos AA, Vallianou NG, Panagiotakos DB, et al. An inverse relationship between cumulating components of the metabolic syndrome and serum magnesium levels [J]. Nutrition Res. 2008, 28 (10): 659-63.

[33] Sanya EO, Adeyanju OA, Olarinoye JK, et al. Magnesium supplementation did not affect the antiseizure property of ketogenic diet but reduced lipid dysmetabolism [J]. West Afr J Med. 2020, 37 (1): 7-12.

[34] Sheu MJ, Chou PY, Lin WH, et al. Deep sea water modulates blood pressure and exhibits hypolipidemic effects via the AMPK-ACC pathway: an in vivo study [J]. Mar Drugs. 2013, 11 (6): 2183-202. 